4. Turner P, Deakin M. Percutaneous endoscopic gastrostomy tube removal and replacement after 'buried bumper syndrome': the simple way. Surg Endosc 2009; 23: 1,914-1,917.

5. Ballester P, Ammori BJ. Laparoscopic removal and replacement of tube gastrostomy in the management of buried bumper syndrome. The Internet Journal of Surgery 2004; 5

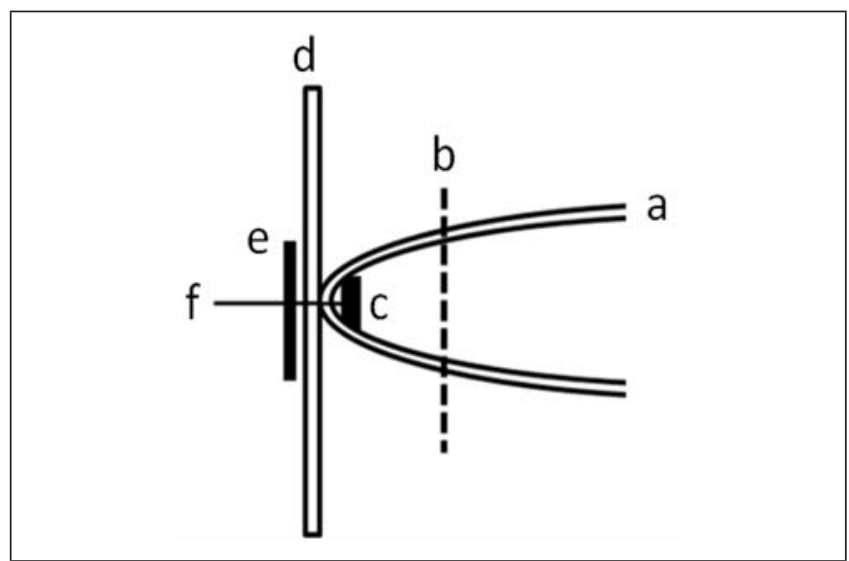

Figure 1 Schematic representation of the procedure $(\mathrm{a}=$ anterior stomach wall; $b=$ staple line; $c=$ internal buried bumper; $d=$ anterior abdominal wall; $e=$ external flange; $f=$ percutaneous endoscopic gastrostomy tube)

\section{Figure-of-eight 'iceberg stitch' facilitates easy removal of supraclavicular lymph nodes}

R Durai, T Oke, M Siddiqui

Queen Elizabeth Hospital, London, UK

\section{CORRESPONDENCE TO}

Rajaraman Durai, E: dr_durai@yahoo.com

We describe a novel 'iceberg stitch' to facilitate easy removal of supraclavicular lymph nodes. The skin and platysma are incised over

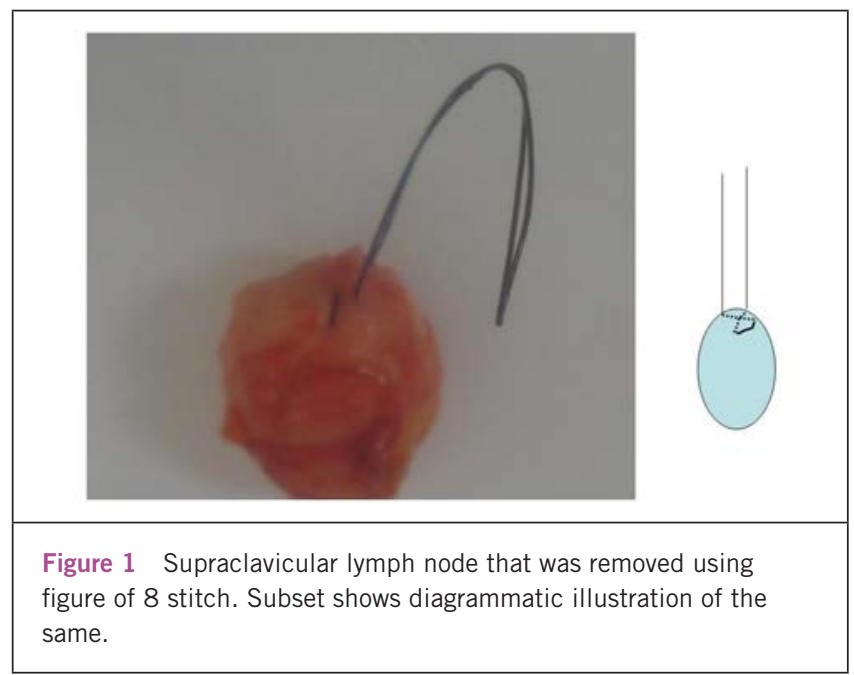

the lymph node. Using an artery clip, the fat pad is opened up. Once the lymph node is seen, a figure-of-eight stitch is applied on the visible part of it, using $3 / 0$ monofilament polypropylene with a small atraumatic round body needle. The stitch is used as a stay so that the node can be dissected all around. A figure of eight makes the suture less likely to cut through. The overall risk of tumour seeding is minimised compared to using a tissue holding forceps and rupturing the capsule.

\section{A useful technique for retrieving the distal segment of a fractured femoral nail}

\section{GT Foley, NPM Jain, PD Dunkow}

Blackpool Victoria Hospital, UK

\section{CORRESPONDENCE TO}

Giles Foley, E: gilestfoley@me.com

We report a technical tip for removing the distal portion of a fractured intramedullary femoral nail. Although retrieving the proximal portion of the implant is often easily achieved, the distal fragment presents a conundrum. We recommend the use of a 'bone corkscrew', most commonly used in hip hemiarthroplasty surgery.

Following removal of the proximal segment of nail, we advise passing the corkscrew through the same channel and engaging the distal segment with the corkscrew thread. To assist with the corkscrew grip within the implant, we further recommend leaving the distal locking bolt in position until satisfactory purchase has been achieved.

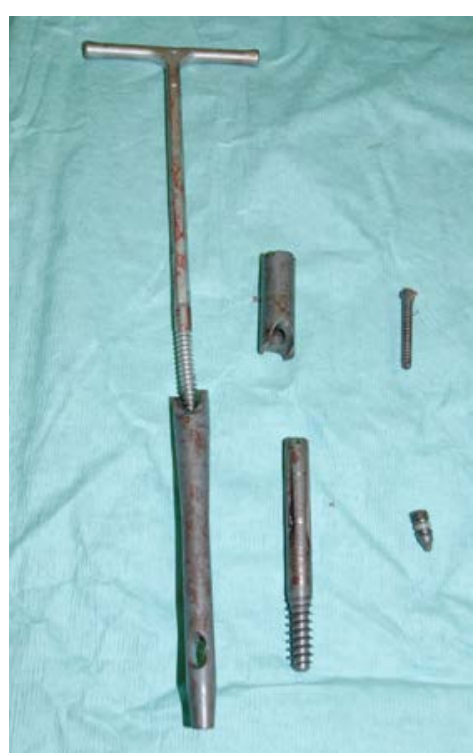

Figure 1 Corkscrew and distal fragment construct with (clockwise from top left) proximal fragment, distal locking bolt, set screw and lag screw 